\title{
UNA FILOSOFÍA SIN INTENCIÓN POLÍTICA MARTIN HEIDEGGER Y EL NACIONAL-SOCIALISMO
}

Hernán Moheno*

En 1962, en Berna Guido Schneeberger con su Nachlese zu Heidegger, y unos años después Karl Löwith, Georg Lukács y Jean Michel Palmier, hicieron explícita la magnitud y formalidad de la relación entre Martin Heidegger, "rey secreto del pensamiento del siglo veinte", ${ }^{1}$ con el nacional-socialismo. Posteriormente en mayo de 1976, la revista alemana Der Spiegel, publicó una entrevista en la que el autor de Sein und Zeit (Ser y Tiempo) buscaba aclarar la ‘sombra que pesaba sobre su obra' por los eventos relacionados con el año 1933. En 1987, el chileno Víctor Farías publicó en París la obra que finalmente desataría la mayor discusión y controversia sobre el pensador y sus nexos con el Tercer Reich, Heidegger y el nazismo.

El presente trabajo parte de dicha discusión, que inicia en 1987 y continúa siendo abordada hasta mediados de los noventa en obras como la compilación de Richard Wolin. ${ }^{2}$ Muchos pensadores han tratado de fortalecer y argumentar las motivaciones del filósofo alemán, pero el hecho es que la figura y pensar de Martin Heidegger son ya inseparables del nazismo. Por mi parte buscaré encontrar qué relación existió

* Presidente Fundación Cultural Baur, ONG asociada a la ONU.

${ }^{1}$ Citada en Francisco Gil Villegas, “Heidegger y el nazismo”, La Jornada Semanal, n 15, sept. 1989, p. 39.

${ }^{2}$ A Critical Reader, 1993, London, The MIT Press. 


\section{HERNÁN MOHENO}

entre el pensamiento del filósofo alemán y su compromiso político con el nazismo a la luz del debate académico mencionado, estudios sobre el nacional-socialismo y parte de la obra de Heidegger. Este artículo busca ser lo más consistente posible, mas consciente de la complejidad del tema no pretende ser un tratamiento exhaustivo del mismo. A su vez, el presente trabajo se encuentra enmarcado dentro de un mayor debate académico sobre la relación entre los grandes pensadores de Occidente y su impacto real en la práctica política. Finalmente, queriendo ser congruente con el pensamiento heideggeriano, pienso que quien busque la verdad -en el sentido griego de la $\alpha \lambda \eta \theta \varepsilon \iota \alpha$ (aletheia) ${ }^{3}$ deberá cuestionarse y hacer el ejercicio de levantar los velos existentes en este proceso de desconstrucción para encontrar la relación entre Heidegger y el nazismo.

La tesis central que presento en las páginas siguientes, es que el compromiso de Heidegger con el régimen del Tercer Reich fue temporal y de carácter político, descarto que las obras anteriores y posteriores de Heidegger al período 1933-1934 tengan fundamentos nacionalsocialistas y menos aún antisemitas como lo planteó Farías. Descarto a Heidegger como teórico nazi, también descarto la influencia nazi en su pensamiento. La única relación existente es temporal y no causal; dicha relación que está vinculada a la interpretación que Heidegger hiciera sobre la esencia del nacional-socialismo - o al menos la asumida en sus primeros años-que concuerda con algunas nociones de su pensamiento sobre el entendimiento del dasein (ser ahí) ${ }^{4}$ en el caso nazi, del pueblo alemán. Lo anterior puede explicar por qué el pensador estuvo involucrado con el nacional-socialismo.

El mecanismo mediante el cual abordaré esta tesis es sencillo. Inicialmente haré una breve introducción a la vida y pensamiento de Heidegger (I), a continuación presentaré un marco teórico para el nacional-socialismo (II); y finalmente a la luz del pensamiento heideggeriano y los

${ }^{3}$ Sin velo o cubrimiento, a diferencia de juicio de adecuación entre cosa e intelecto.

${ }^{4}$ Utilizaré indistintamente 'ser ahí’ o dasein. 
principales argumentos de Farías, ubicados dentro del debate sobre Heidegger y el nazismo, presentaré la relación entre su obra filosófica y su compromiso político (III).

The gale that blows through Heidegger's thinking -like that which still, after thousands of years, blows to us from Plato's work- is not of our century. It comes from the primordial, and what it leaves behind is something perfect which, like everything perfect, falls back to the primordial.

Hannah Arendt ${ }^{5}$

Para entender mejor al pensador alemán, considero necesario hacer una muy breve mención sobre los más importantes aspectos de su vida y conceptos en su obra; un estudio que considero profundo y completo al respecto fue publicado en 1994 por Rüdiger Safranski. ${ }^{6}$ Lo que originalmente era un texto sobre Aristóteles se convirtió hacia 1927 en una investigación fenomenológica, y su más grande obra “con un lugar eminente en el pensamiento filosófico de nuestro siglo”, 7 Sein und Zeit. Como resultado del impacto y trascendencia inmediata de esta obra, Heidegger se convierte en sucesor de Husserl en Friburgo. Para 1929 inicia sus trabajos más formales sobre la cuestión de la metafísica y en 1933 se une al Partido nazi; nombrado por el régimen como rector de la Universidad de Friburgo el 27 de mayo, ${ }^{8}$ ocuparía el

${ }^{5}$ Citada en Rüdiger Safranski, Martin Heidegger: between good and evil, 1998, Londres, Harvard University Press, trad. Ewald Osers, p. 1.

${ }^{6}$ Rüdiger Safranski, op. cit.

${ }^{7}$ Jürgen Habermas, Martin Heidegger. L'ouvre et l'engagement, sept. 1988, París, Editions du Cerf, p. 9.

${ }^{8}$ El discurso que Heidegger pronunció en la toma del rectorado, "La defensa de la Universidad alemana” ("Die Selbstbehauptung der deutschen Üniver- 


\section{HERNÁN MOHENO}

cargo menos de un año, renunciando en 1934 por diferencias irreconciliables con el gobierno y el partido. A partir de ese momento y hasta el fin del Tercer Reich, Heidegger permanece constantemente vigilado por agentes de la Gestapo. Para 1940 se dedica a dar una cátedra sobre Nietzsche y discute críticamente el poder ideológico del nacional-socialismo; continúa enseñando hasta 1944. A mediados de 1945 toda la facultad filosófica es evacuada al Castillo de Wildenstein y en Julio se presenta ante el comité de desnazificación donde Karl Jaspers, un antiguo colega, declara en su favor. Más tarde escribe la Carta sobre el Humanismo y permanece como docente, continuando su trabajo como filósofo hasta su muerte en 1976. Cinco días después de su muerte, la revista Der Spiegel publicó una entrevista que él solicitó y realizó en 1966 para esclarecer sus nexos con el nazismo.

Heidegger abordó a los grandes clásicos del pensamiento, como Platón, Aristóteles, Heráclito, san Agustín, Hegel y Kant. Siempre planteando nuevas preguntas, principalmente sobre el Ser; buscaba así devolverle el sentido a la pregunta que había perdido la modernidad. En palabras del mismo Heidegger: "La finalidad de las consideraciones hechas hasta aquí era hacer la exégesis ontológico-existenciaria del todo original del 'ser ahí’ fáctico, en lo que respecta a las posibilidades del existir propio e impropio, desde su fundamento. Este fundamento, y por ende el sentido del ser de la cura, se reveló ser la temporalidad."9 Para él, el hombre se encontraba en una crisis profunda por haber dejado de hacerse los principales cuestionamientos ${ }^{10}$ metafísicos y

sität”) es discutido por la mayor parte de los pensadores que abordan su relación con el nazismo, principalmente Víctor Farías, como un texto que conjuga de forma indiscutible la esencia de su pensamiento y el nacionalsocialismo. En la última parte de este trabajo haré una referencia más detenida sobre el mismo.

${ }^{9}$ Martin Heidegger, El Ser y el tiempo, 2000, 2a., México, FCE, p. 469.

${ }^{10}$ Sobre dicho cuestionamiento Heidegger dice: "Hay que hacer la pregunta que interroga por el sentido del ser. Si es una pregunta fundamental o incluso la pregunta fundamental, tal pregunta ha menester de que se llegue a 'ver a través’ de ella adecuadamente” (ibid., p. 14). 
ontológicos. ${ }^{11}$ Así desarrolla la filosofía del dasein ${ }^{12}$ que se plantea ante la exégesis del ente, cuestionándose sobre la existencia misma del Ser. ${ }^{13}$ Heidegger se remonta en un ejercicio de desconstrucción de los conceptos y verdades en un intento de llegar a la primera concepción de la pregunta sobre el ser a partir de la existencia del hombre como dasein que se interroga sobre su propio origen. ${ }^{14}$

\section{II}

Aunque a partir del holocausto se han escrito incontables obras sobre el nazismo, la mayor parte de estos textos abordan el tema desde el acontecimiento histórico o bajo juicios morales, sin embargo es muy limitada la literatura que lo explica como fenómeno político desde una visión teórica positiva. Para presentar un marco teórico sobre el concepto del nacional-socialismo como movimiento e ideología, recurriré principalmente a Juan J. Linz, y de manera complementaria a

11 “Todo este preguntar -ontología en el sentido más amplio y sin limitación de direcciones ni tendencias ontológicas- ha menester él mismo de un hilo conductor. (...) La misma investigación ontológica bien comprendida da a la pregunta que interroga por el ser su preeminencia ontológica por encima de la mera recepción de una tradición” (ibid., p. 20).

12 "Este ente que somos en cada caso nosotros mismos y que tiene entre otros rasgos la 'posibilidad de ser' del preguntar, lo designamos con el término 'ser ahí'. El hacer en forma expresa y de 'ver a través' de ella la pregunta que interroga por el sentido del ser, pide el previo y adecuado análisis de un ente (el 'ser ahí') poniendo la mira en su ser” (ibid., p. 17).

13 “La 'esencia' de este ente está en su 'ser relativamente a'. El 'qué es' (essentia) de este ente, hasta donde puede hablarse de él, tiene que concebirse partiendo de su ser (existentia)" (ibid., p. 54).

${ }^{14}$ En el último apartado cuando aborde la cuestión sobre el vínculo del pensamiento de Heidegger y el nacional-socialismo profundizaré sobre el contenido filosófico de Sein und Zeit; este último párrafo sólo busca hacer una primera aproximación al contenido y forma del texto. 


\section{HERNÁN MOHENO}

Hannah Arendt y a George Steinmetz, quien aporta una visión más filosófica de gran utilidad para nuestro propósito.

El trabajo de Linz, como lo menciona Francois Furet, parte de las categorías políticas introducidas originalmente por Hannah Arendt sobre el totalitarismo, siendo el estalinismo y el nazismo los dos ejemplos del siglo Xx. ${ }^{15}$ Para Linz, el nacional-socialismo es una ideología y movimiento político totalitarista definido a partir de lo que rechaza, basado en el nacionalismo exacerbado, la conservación de lo propio ante enemigos políticos e ideológicos y formado por un sistema de partido único que incorpora el sentir popular; el nazismo antepone a la solidaridad de clases, la solidaridad entre individuos nacionales; se enfoca en una forma de régimen que reorganiza completamente la vida política, ideológica y social. "Las posiciones antitéticas del fascismo son esenciales para su entendimiento [...] es antiliberal, antiparlamentario, antidemocrático, antimarxista y particularmente anticomunista, anti o aclerical, antiburgués, en cierto sentido y anticapitalista." ${ }^{\text {"Como }}$ movimiento está orientado al futuro y no busca la continuidad conservadora con el pasado reciente, mas se relaciona con la tradición histórica nacional. Distinguido por defender lo propio ante valores externos, el nacional-socialismo alemán es además un régimen antisemita con matices extremos de racismo. Se proclama en contra de los sistemas políticos de principios del siglo, por ser éstos incapaces de enfrentar la crisis política existente.

Sobre el carácter antisemita del nazismo, Linz profundiza, “el antisemitismo en la Europa de principios de siglo, particularmente en Europa del Este (Pulzer, 1964; Massing, 1949), tenía una larga tradición, y dondequiera que hubiesen judíos, el fascismo tendía hacia esa perspectiva que enfatizaba el carácter anacional y cosmopolita del judaísmo, particularmente del sionismo”. ${ }^{17}$

${ }^{15}$ François Furet en Juan Linz, Totalitarian, p. 4-5.

${ }^{16}$ Juan J. Linz, Totalitarian and Authoritarian Regimes, 2000, Boulder, Lynne Rienner Publishers, p. 220.

${ }^{17}$ p. 221. 
Su autoritarismo, explica Linz, tiene origen en la necesidad de combatir al comunismo. El rechazo total a las políticas de la democracia liberal es explicado por estar basada en la participación plural, la libre expresión de intereses, su compromiso horizontal sobre el interés colectivo y, como ya fue mencionado, por su incapacidad de resolución de conflictos. El movimiento tuvo un rápido éxito y se consolidó como régimen con nuevas formas y estilos de organización política que ofrecían oportunidad de acción, involucramieto, participación y rompimiento con la monotonía. Además da consuelo a una generación heroica -aquella de la Primera guerra mundial-: satisfacción de elementos psicológicos, rompimiento con las convenciones burguesas y patrocinio de la lucha generalizada y unificada en contra de los enemigos de la nación. ${ }^{18}$

Cabe agregar a lo ya planteado, lo que Hannah Arendt expresó en cuanto a que el nazismo fue un movimiento pan-germánico que buscaba transformar partidos en movimientos, con la capacidad de adaptar sus políticas a objetivos de corta y amplia temporalidad. Distinguido como movimiento, se caracteriza por dar importancia al ánimo social y a la necesidad de dinamismo: "el Estado, aún como dictadura de partido único, era percibido como un camino de constante cambio ante las necesidades cambiantes de un movimiento creciente”. Es el Estado, finalmente, la máxima autoridad una vez que esté en manos de los miembros de la liga pan-germánica. ${ }^{19}$

Finalmente, bajo este diseño de formulación daré un marco teórico que haga más claro el entendimiento del tipo de relación entre Heidegger y el nacional-socialismo como movimiento político; en este caso es enriquecedora la visión de Steinmetz sobre la génesis y conceptualización del nazismo. Para él, existe un excepcionalismo en la historiografía

\footnotetext{
${ }^{18}$ Para una lectura más profunda sobre los conceptos aquí planteados, véase Juan J. Linz, op. cit., p. 14-7, 20-4, 118-28, 218-24.

${ }^{19}$ Véase Hannah Arendt, The Origins of Totalitarianism, 1979, Londres, Harcourt Brace \& Company, p. 250-65.
} 


\section{HERNÁN MOHENO}

alemana que produce resultados únicos; así, la tesis del Sonderwg. ${ }^{20}$ En ella propone que el nazismo está formado por un complejo y cambiante discurso político como camino especial a la modernidad, formado por ciertos textos e ideas, no por planteamientos unificados. Para este autor el origen del nazismo encuentra sus raíces en acontecimientos históricos alemanes como la reforma protestante y los efectos de las guerras napoleónicas que dan como resultado una auténtica cultura germana. Agrega que el nazismo surgió por la falta de una revolución burguesa democrática durante el siglo XIX, aunado a la debilidad del liberalismo y del racionalismo. ${ }^{21}$ Finaliza diciendo que el nazismo se consolida a partir de retomar antiguos valores germanos, pero casi todos fundados en la historiografía alemana.

\section{III}

Con el fin de relacionar ahora la obra de Heidegger con la ideología nacional-socialista, abordaré los principales argumentos presentados por los exponentes que más contribuyeron desde 1987 al debate sobre el nazismo de Heidegger. Víctor Farías propone como tesis central de su obra, demostrar a través de tres niveles de análisis ${ }^{22}$ que el compro-

\footnotetext{
${ }^{20}$ La tesis del sonderwg alemán o camino único a la modernidad, fue originalmente planteada por Wehler para explicar el origen distintivo del nacionalsocialismo, caso excepcional sobre un mecanismo historicista causal. Para profundizar al respecto, véase George Steinmetz, "German exceptionalism and the origins of Nazism: the career of a concept" en Ian Kershaw y Moshe Lewin, Stalinism and Nazism: Dictatorships in Comparison, 1997, Cambridge, Cambridge University Press, p. 251-53 y Hans-Ulrich Wehler, The German Empire 1871-1918, 1985, Berg, Leamington Spa, p. 7.

${ }^{21}$ Véase George Steinmetz, p. 260.

${ }^{22}$ Estos tres niveles son "el del contexto histórico objetivo, el de la práctica concreta del pensador que adopta ésta o aquella opción política y el de la significación sistemática de las ideas que formula” (Víctor Farías, Heidegger y el nazismo, 1989, Barcelona, Muchnik, p. 29).
} 
miso político de Heidegger no fue temporal, que existía en su obra y en su pensar en general sólidas raíces nazis e incluso antisemitas.

Para esto, Farías presenta las conclusiones de una investigación profunda-probablemente la mayor realizada sobre los vínculos nazis de Heidegger- revisando las distintas etapas de la vida del filósofo. Para Farías toda la literatura heideggeriana está predispuesta al nacional-socialismo desde su primer publicación en 1910. Un argumento central en Farías sobre el antisemitismo de Heidegger es su admiración a Abraham de Sancta Clara, un ‘conocido’ promotor del pensamiento antisemita. ${ }^{23}$ Farías explica la separación de Heidegger y el régimen como una frustración por la predominancia de otras facciones del partido que no le permitirían ascender políticamente. Además de probar -según Farías- que Heidegger era antisemita, argumenta que la actividad política y pública de Heidegger legitimaron e influenciaron al nacional-socialismo alemán. ${ }^{24}$

Una lectura superficial de Farías parece demostrar el nazismo de Heidegger, política e ideológicamente; sin embargo leyendo cuidadosamente y a la luz de otros críticos como Pierre Bourdieu, Richard Wolin, Jürgen Habermas, Karl Löwith, Karl Jaspers, Francisco Gil Villegas, la obra de Farías realmente no aporta nada a la pregunta planteada al principio de este trabajo. Tanto los datos biográficos como sus interpretaciones sobre la filosofía de Heidegger son manipulados, y como diría Tracy Strong, sus demostraciones causales no pasan de 'suena como', 'parece que’ y preguntas retóricas. ${ }^{25}$ Sobre esta discusión, ahonda Bourdieu:

Detractores que recusan la filosofía en nombre de la afiliación al nazismo o laudatarios que separan la filosofía de la pertenencia al nazismo, todos están de acuerdo en ignorar que la filosofía de Heidegger podría ser sólo la sublimación filosófica,

${ }^{23}$ Ibid., p. 57-74.

${ }^{24}$ Ibid., p. 141-90 y 249-62.

${ }^{25}$ Tracy Strong, “Book Review: Heidegger and Nazism”, en The American Political Science Review, vol. 84, sept. 90, p. 962-65. 


\section{HERNÁN MOHENO}

impuesta por la censura específica del campo de producción filosófica, de los principios políticos o éticos que determinaron la adhesión del filósofo al nazismo. ${ }^{26}$

Las críticas más formales a la obra de Farías, destacan que, en efecto, no aporta datos concretos ni novedosos, y que está "plagada de incontables falacias, sofismas y asociaciones tramposas”. ${ }^{27}$ Al respecto de la mención de Abraham de Sancta Clara, Heidegger aborda fundamentalmente su mensaje místico; por cierto, gran parte de intelectuales alemanes inclusive judíos expresaron su admiración por este personaje. ${ }^{28}$ Ahondando sobre el supuesto antisemitismo de Heidegger -que para Farías es la fuente que vincula su pensamiento con el nazismocabe recordar la relación de éste con pensadores judíos como Husserl, Marcuse, Hannah Arendt y Karl Löwith, y otros como Max Scheler a quien consideró “el único pensador que había entendido en toda su magnitud la profundidad del pensamiento de Sein und Zeit”. ${ }^{29}$ Adicionalmente como rector de Friburgo, ante los despidos masivos de judíos, Heidegger intervino por dos profesores, Eduard Fraenkel y Georg von Hevesy, solicitando al Ministro de Educación permitirles continuar en la universidad. ${ }^{30}$

Sobre el compromiso nacional-socialista de Heidegger y su pensamiento es necesario hacer una diferenciación. No queda ninguna duda al respecto que Heidegger se comprometió con el movimiento como intelectual e incluso como activista político, ofreciendo un apoyo real al régimen. Sin embargo la influencia de Heidegger en la promoción e ideología nazi durante su afiliación al partido fue mucho menor que la que pretende Farías. Dice Pierre Bourdieu respecto de la proclamación de mayo de 1933: "el discurso La defensa de la Universidad, que

${ }^{26}$ Véase Pierre Bourdieu, La ontología política de Martin Heidegger, 1991, Barcelona, Paidós, p. 15.

${ }^{27}$ Véase Francisco Gil Villegas, op. cit., p. 37.

${ }^{28}$ Ibid., p. 38.

${ }^{29}$ Ibid., p. 39.

${ }^{30}$ Véase Rüdiger Safranski, op. cit., p. 254. 
ha sido frecuentemente invocado para demostrar la pertenencia de Heidegger al nazismo, puede encontrar sitio en una historia del pensamiento heideggeriano tan puramente interna como la de Richardson". ${ }^{31}$ Mientras que sobre el discurso de la toma del rectorado Karl Löwith comenta: “al final de la conferencia, el auditor no sabe si debe abrir los Presocráticos de Diels o enrolarse en las filas de las SA. No puede uno por eso limitarse a juzgar este discurso según un punto de vista, o puramente político o puramente filosófico". ${ }^{32}$ Sobre este discurso algunos políticos también comentaron: "no tendrá efecto alguno en la política [...] y eso es una pena en especial para las políticas futuras”. 33

Existieron también opiniones similares en cuanto a su desempeño político, Safranski hace un listado de los comentarios que alrededor de 1934 se hicieron al respecto. Tan sólo mencionaré algunos para ilustrar el argumento:

Walter Gross, cabeza de la Oficina racial del Partido nazi, concluyó sobre la versión nacional-socialista de Heidegger, que era carente de elementos útiles para el nacional-socialismo. [...] Al interior de los centros de poder nazi, Heidegger era visto como alguien ‘jugando al nacional-socialismo’. Fue Gross quien advirtió al ideólogo nazi Alfred Rosenberg en contra de Heidegger, cuando a finales del verano de 1934, su nombre aparecía entre los candidatos para dirigir el Nazi Dozentenakademie que buscaba ser una escuela ideológica para jóvenes científicos. Para esto Gross hizo referencia a los comentarios de expertos como Jaesch y Krieck, así como a reportes no favorables sobre las “actividades de Heidegger en Friburgo". 34

${ }^{31}$ Véase Pierre Bourdieu, op. cit., p. 17.

${ }^{32}$ Karl Löwith, "Les implications politiques de la philosophie de l'existence chez Heidegger”, Les Temps modernes, n 14, 1946, p. 343-60.

${ }^{33}$ Véase Rüdiger Safranski, op. cit., p. 254.

${ }^{34}$ Ibid., p. 269. 


\section{HERNÁN MOHENO}

A su vez, hacia abril de 1933 Heidegger le escribía a Jaspers diciendo que todo dependería de encontrar en la filosofía el 'punto correcto de ataque’ dentro de la 'nueva realidad’ y auxiliarle a ser escuchada, esta 'nueva realidad' es ahora la revolución nacional-socialista. ${ }^{35}$

He mencionado ya de forma muy breve algunas características sobre el desempeño político de Heidegger; ahora abordaré la cuestión de la relación con su pensamiento teórico. La visión del régimen sobre su obra y en especial Sein und Zeit, era similar a la que existía sobre su desempeño como rector. En 1934, Ernst Krieck el filósofo oficial del movimiento nazi, publicó en la revista Volk im Werden,

En Ser y Tiempo, Heidegger consciente y deliberadamente filosofa sobre el acontecer diario -no hay nada en él sobre la nación o el estado, sobre la raza, o cualquier otro de los valores de nuestra ideología nacional-socialista. Si de momento su discurso rectoral aparece como heroico, entonces es porque fue adecuado a 1933, un discurso en total contradicción con la actitud general de Ser y Tiempo (1927) y ¿Qué es metafísica? $(1931)^{36}$

Safranski menciona que "Ernst Krieck y Erich Jaensch -ideólogos nazis- no pudieron encontrar en la filosofía de Heidegger elementos a favor de la visión del nacional-socialismo”. ${ }^{37}$ Por otra parte, el pensamiento filosófico heideggeriano no contiene fundamentos políticos nacional-socialistas. Partiendo del marco teórico presentado en el apartado II, es claro que la obra de Heidegger orientada hacia la pregunta ontológica del Ser y posteriormente hacia la metafísica, no contiene ideas sobre la organización del Estado. Ideológicamente Sein und Zeit conduce al lector a un cuestionamiento sobre el Ser a partir de su

${ }^{35}$ Véanse las Cartas entre Heidegger y Jaspers en Rüdiger Safranski, op. cit., p. 252.

${ }^{36}$ Ibid., p. 268.

${ }^{37}$ Ibid. 
dasein, un mero proceso filosófico y no un activismo político. La única relación que podría existir con la esencia del nacionalismo en la literatura heideggeriana es aquella sobre la autenticidad y la historicidad. ${ }^{38}$ Comparada con la concepción de Linz presentada anteriormente, la obra de Heidegger, no habla sobre movimientos políticos o grupos únicos dirigentes como el Partido Nacional-socialista, ni tampoco busca la solidaridad del pueblo alemán para reorganizar la vida política, ideológica y social, en cuanto a pretensiones ideológicas implícitas, puede buscar persuadir al individuo al cuestionamiento sobre el Ser. La obra de Heidegger tampoco se postula en contra de los conceptos antitéticos del nazismo mencionados anteriormente y esenciales para explicar el movimiento -como anticomunismo o antiparlamentarismo.

Existen sin embargo algunas características del nazismo -sobre todo bajo la concepción de Steinmetz y algunos postulados de Linz- que en 'su esencia’ pudiesen ser compatibles con el pensamiento de Heidegger; mas no son de índole práctica sino normativa. Encuentro cierto paralelismo en que en los orígenes Sein und Zeit explica que la necesidad de cuestionarse sobre el Ser deriva de una crisis constante del pensamiento que no es resuelta, y el nazismo también se reconoce como respuesta a la crisis del pueblo alemán. Para la explicación de conceptos, Heidegger busca romper con las nociones del pasado reciente y llegar a las concepciones originales; el nazismo también buscaba relacionarse con la tradición histórica. Ideológicamente, el nazismo, como ya fue mencionado en el apartado II, busca consolidarse a partir de retomar antiguos valores; de alguna manera el pensamiento de Heidegger también se reafirma en el pensamiento griego. Finalmente, el nazismo era percibido como un camino de constante cambio ante las necesidades cambiantes de su momento; el cuestionamiento ontológico del ser que Heidegger propone también es cambiante, ya que siempre parte del dasein que no es uno con el paso del tiempo.

38 “Esta elemental historicidad del 'ser ahí' puede permanecerle oculta a este mismo. Pero también puede descubrirse de cierto modo y experimentar un peculiar cultivo. El 'ser ahí' puede descubrir la tradición, conservarla y seguirla expresamente” (El Ser, p. 30). 


\section{HERNÁN MOHENO}

Las interpretaciones que hago en el párrafo anterior no muestran, lógicamente, que exista una relación entre la filosofía heideggeriana y la ideología nazi, pero serán de utilidad para explicar por qué Heidegger a partir de su propia obra explicó el nacional-socialismo. La mencionada obra de Pierre Bourdieu es enriquecedora para construir puentes entre el pensamiento de Heidegger y el nacional-socialismo.

Antes de pasar a la interpretación final sobre la relación que existió entre el pensamiento de Heidegger y el nazismo, voy a presentar un párrafo extraído de la cátedra impartida por Heidegger en 1934 sobre la Lógica.

...existe una transformación de 'lo mío' en 'lo nuestro'. “El ser no es una determinación distintiva del 'yo'”. Lo que es importante es el 'nosotros'. En las tareas del 'yo', el individuo pierde suelo; está 'parado en donde se pierde el ser' pues busca al ser en el lugar equivocado, en el 'yo'. El ser sólo puede ser encontrado en el 'nosotros', aunque no cualquier grupo de personas representa necesariamente un tal 'nosotros'. La distinción entre autenticidad e inautenticidad radica en lo llano del nosotros. El nosotros inauténtico es el ‘ellos’, el nosotros auténtico es la nación que se defiende a sí misma como un hombre. El total de una nación, es por ende un hombre a gran escala. $^{39}$

Interpretando todo lo ya planteado, Heidegger vio al nacional-socialismo como el proceso para encontrar la verdad sobre la existencia del Volk (pueblo) alemán. Bajo esta luz la hipótesis original no es completa, faltaría agregar que Heidegger vislumbró al movimiento nazi como un ejercicio que entendía como el de la cuestión fenomenológica que se preguntaba sobre el ser. Y que de esta forma creyó que

${ }^{39}$ Logic. Lectures, summer semester 1934 (citada por Víctor Farías, op. cit., p. 26). 
el nacional-socialismo determinaría la respuesta a la cuestión del dasein del pueblo alemán. ${ }^{40}$

Siguiendo esta línea de pensamiento, al cuestionarse sobre el ser alemán y el nacional-socialismo como expresión de su dasein, ${ }^{41}$ se desconstruyó a sí mismo hasta sus orígenes -librándose de las concepciones que con el tiempo se formó sobre sí- para encontrar en su autenticidad originaria la ontología del Volk alemán. Bajo el supuesto de que en efecto Martin Heidegger utilizó su ontología para explicar la esencia del nazismo, podemos explicar -no justificar- su firme adhesión al Partido como activista intelectual. Como dice Bourdieu: "los denunciadores más resueltos de los comprometimientos del autor de Sein und Zeit con el nazismo, nunca buscaron en los mismos textos los indicios, los reconocimientos o las huellas capaces de anunciar o de aclarar los compromisos políticos de su autor”. ${ }^{42}$

\section{Conclusión}

La esencia teórica de Sein und Zeit permitió a Heidegger explicar el nazismo (a partir de su proclamación en 1933) como el proceso fenomenológico que se cuestionaba por el dasein del volk alemán y la 'historicidad del ser', ${ }^{43}$ esto lo llevó a sumarse al movimiento bajo lo que él creyó como la defensa del pueblo alemán por medio del ‘auto-

40 “El ser del 'ser ahí' quiere decir: pre-ser-se-ya-en (el mundo) como ser-cabe (los entes que hacen frente dentro del mundo).” Este ser es lo que constituye, en conclusión, el significado del término 'cura'. Véase Martin Heidegger, El Ser, p. 213.

41 “El 'ser ahí' existe fácticamente. Se pregunta por la unidad ontológica de existenciariedad y facticidad o por la esencial inherencia de ésta a aquélla" (El Ser, p. 200-1).

42 Pierre Bourdieu, op. cit., p. 13.

43 “El 'ser ahí' tiene fácticamente en cada caso su 'historia' y puede tenerla porque el ser de este ente está constituido por la historicidad” (Martin Heidegger, El Ser, p. 412). 


\section{HERNÁN MOHENO}

gobierno ${ }^{, 44}$ de la universidad, bajo la convicción de estar practicando el 'servicio al conocimiento'. ${ }^{45}$

Cumpliéndose lo anterior, la relación que existe entre su pensamiento teórico y su compromiso político, es la de eje explicativo que le permitió por medio de la desconstrucción del cuestionamiento, explicar la 'historicidad del dasein' del pueblo alemán mediante el nacionalsocialismo. ${ }^{46}$ La relación es pues de índole interpretativo, útil para Heidegger, y sólo él pudo comprenderla así. Por lo tanto puede decirse que su interpretación del nazismo fue esencial para explicar su corto período de militancia.

Si nos preguntásemos ahora ¿es la obra Sein und Zeit una explicación o justificación del nazismo?, la respuesta es claramente no. Sin embargo, podría recibir como réplica, ¿por qué lo utilizó Heidegger entonces para interpretarlo?, y la respuesta sería, porque dicha obra era la concepción que el autor guardaba sobre el cuestionamiento más puro sobre una determinada forma de existencia, y probablemente, sólo probablemente, intentó encontrar a través de este texto la explicación del dasein del pueblo alemán en 1933. ${ }^{47}$

La interpretación que Martin Heidegger realizó sobre la esencia del 22 nazismo -como él mismo lo reconociera después- ${ }^{48}$ fue errónea; la única utilidad de relacionar Sein und Zeit con el nacional-socialismo es para explicar porqué el mismo Heidegger fue nazi. Tendría que

44 Traducción de self-governance. Véase Martin Heidegger, "The SelfAssertion of the German University”, en Richard Wolin, op. cit., p. 29.

${ }^{45}$ Ibid., p. 35.

46 “"El análisis de la historicidad del 'ser ahí' trata de mostrar que este ente no es 'temporal' por estar dentro de la historia, sino que, a la inversa, sólo existe y puede existir históricamente por ser temporal en el fondo de su ser" (El Ser, p. 407).

${ }^{47}$ Un ejercicio constructivo a este respecto -y que sin embargo por extensión no realizo- sería el de establecer un contrafactual, que se pregunte si la filosofía de Heidegger podría haber interpretado igualmente el dasein del pueblo inglés, francés o judío.

${ }^{48}$ Véase la entrevista en Der Spiegel, en Richard Wolin, op. cit., p. 91-116. 
finalizar coincidiendo con Karl Löwith - discípulo judío de Heideggersobre la implicación del compromiso político: “aquellos que no puedan entender porque él actuó de esta manera han fallado en comprenderlo [...] la posibilidad de una filosofía política heideggeriana no nació como un lamentable descuido, mas de la misma concepción de la existencia que simultáneamente combate y absorbe el 'espíritu de su época,", 49

${ }^{49}$ Véase Karl Löwith, op. cit., p. 343. 
